ARTICLE

Received 23 Apr 2013 | Accepted 6 Sep 2013 | Published 3 Oct $2013 \quad$ DOl: 10.1038/ncomms3566

\title{
Cobalt phosphate-modified barium-doped tantalum nitride nanorod photoanode with $1.5 \%$ solar energy conversion efficiency
}

Yanbo Li ${ }^{1}$, Li Zhang ${ }^{1}$, Almudena Torres-Pardo², Jose M. González-Calbet², Yanhang Ma ${ }^{3}$, Peter Oleynikov ${ }^{3}$, Osamu Terasaki ${ }^{3,4}$, Shunsuke Asahina ${ }^{5}$, Masahide Shima ${ }^{5}$, Dongkyu Cha ${ }^{6}$, Lan Zhao ${ }^{6}$, Kazuhiro Takanabe ${ }^{6}$, Jun Kubota ${ }^{1} \&$ Kazunari Domen ${ }^{1}$

Spurred by the decreased availability of fossil fuels and global warming, the idea of converting solar energy into clean fuels has been widely recognized. Hydrogen produced by photoelectrochemical water splitting using sunlight could provide a carbon dioxide lean fuel as an alternative to fossil fuels. A major challenge in photoelectrochemical water splitting is to develop an efficient photoanode that can stably oxidize water into oxygen. Here we report an efficient and stable photoanode that couples an active barium-doped tantalum nitride nanostructure with a stable cobalt phosphate co-catalyst. The effect of barium doping on the photoelectrochemical activity of the photoanode is investigated. The photoanode yields a maximum solar energy conversion efficiency of $1.5 \%$, which is more than three times higher than that of state-of-the-art single-photon photoanodes. Further, stoichiometric oxygen and hydrogen are stably produced on the photoanode and the counter electrode with Faraday efficiency of almost unity for $100 \mathrm{~min}$.

\footnotetext{
${ }^{1}$ Department of Chemical System Engineering, The University of Tokyo, 7-3-1 Hongo, Bunkyo-ku, Tokyo 113 8656, Japan. ${ }^{2}$ Departamento de química Inorgánica, Facultad de Químicas, Universidad Complutense, 28040 Madrid, Spain. ${ }^{3}$ Department of Materials and Environmental Chemistry, Stockholm University, SE-10691 Stockholm, Sweden. ${ }^{4}$ Graduate School of EEWS, WCU, KAIST, Daejeon 305 701, Republic of Korea. ${ }^{5}$ SM Application Group, JEOL Ltd., 12 Musashino 3-Chome Akisima, Tokyo 196 8558, Japan. ${ }^{6}$ Division of Physical Sciences and Engineering, KAUST Catalysis Center, King Abdullah University of Science and Technology (KAUST), 4700 KAUST, Thuwal 23955-6900, Saudi Arabia. Correspondence and requests for materials should be addressed to K.D. (email: domen@chemsys.t.u-tokyo.ac.jp).
} 
$\mathrm{T}$ he globally ongoing solar fuel projects reflect the pressing need for producing fuels from sunlight so that solar energy can be stored and used whenever and wherever it is needed ${ }^{1-3}$. Photoelectrochemical (PEC) splitting of water into hydrogen and oxygen is a promising way to directly convert solar energy into fuel ${ }^{4-}$. Among the proposed configurations for PEC cells $^{6}$, the dual band gap PEC cell constructed by electrically connecting an $n$-type photoanode and a $p$-type photocathode in series is the most economical one that has the potential to realize the $10 \%$ solar-to-fuel conversion efficiency required for practical application. Constructing such a PEC cell requires both a photoanode and photocathode with high activity for water oxidation and reduction. Although many highly active and stable $p$-type photocathodes have been developed in recent years $^{8-12}$, the more challenging task is to develop a photoanode that can stably oxidize water into oxygen under sunlight with high efficiency. The poor stability because of the strong oxidizing conditions and the low efficiency because of the high overpotential of four-electron water oxidation are the major challenges in designing the photoanode. To the best of our knowledge, the solar energy conversion efficiency of singlephoton photoanodes reported so far are below $0.5 \%$ at best ${ }^{13-17}$. Thus, there is still much room for improvement in the activity of the photoanode to achieve high efficiency in an integrated dual band gap PEC cell.

A PEC cell is a complex system, every aspect of which should be optimized to maximize device performance. For the photoanode part, the structure, material properties and co-catalyst modification are the three determining factors of its efficiency. The use of nanostructures is an effective way to improve the efficiency of the photoanode as it results in enhanced carrier collection, improved light absorption and surface area-enhanced charge transfer ${ }^{18}$. Choosing a visible-light-responsive semiconductor with energy band positions that favour water oxidation and reduction is also effective in improving the efficiency of the photoanode. The semiconductor material properties can be further improved by doping with appropriate impurities, a technique that is indispensable in the semiconductor industry. Modification of the photoanode with a suitable oxygen evolution co-catalyst is equally important as it improves the efficiency by lowering the overpotential and preventing photocorrosion. Recently, we reported a highly efficient photoanode made of a vertically aligned tantalum nitride $\left(\mathrm{Ta}_{3} \mathrm{~N}_{5}\right)$ nanorod array modified with an iridium oxide co-catalyst ${ }^{15}$. The photoanode, owing to its nanorod structure and $\mathrm{Ta}_{3} \mathrm{~N}_{5}$ material properties, exhibited state-of-the-art efficiency at the time of reporting. Yet, the solar energy conversion efficiency of this photoanode was still below $0.5 \%$.

Unintentionally doped $\mathrm{Ta}_{3} \mathrm{~N}_{5}$ is an $n$-type semiconductor with a band gap of $2.1 \mathrm{eV}$, capable of absorbing a large portion of the solar radiation, up to a wavelength of $\sim 590 \mathrm{~nm}$. The energy bands of $\mathrm{Ta}_{3} \mathrm{~N}_{5}$ straddle the water redox potentials ${ }^{19}$, which is energetically more suitable for water splitting than most visiblelight-responsive oxides (for example, $\mathrm{Fe}_{2} \mathrm{O}_{3}$ (ref. 14), $\mathrm{WO}_{3}$ (ref. 20) and $\mathrm{BiVO}_{4}$ (ref. 21)), having a conduction band too positive for $\mathrm{H}_{2}$ evolution. $\operatorname{Ta}_{3} \mathrm{~N}_{5}$ has been widely used for both photocatalytic and PEC water splitting $22-28$. Various attempts have been made to increase the activity of $\mathrm{Ta}_{3} \mathrm{~N}_{5}$ by doping with foreign elements, mostly with group IA alkali metals ${ }^{29-31}$. The effectiveness of doping demonstrated with alkali metals is still limited.

Here we demonstrate that the efficiency of the $\mathrm{Ta}_{3} \mathrm{~N}_{5}$ nanorod photoanode is greatly improved by doping the nanorods with barium $(\mathrm{Ba})$ and modifying the surface with cobalt phosphate (Co-Pi) as an oxygen evolution co-catalyst. The Co-Pi-modified Ba-doped $\mathrm{Ta}_{3} \mathrm{~N}_{5}$ (hereinafter $\mathrm{Co}-\mathrm{Pi} / \mathrm{Ba}-\mathrm{Ta}_{3} \mathrm{~N}_{5}$ ) nanorod photoanode yielded a solar energy conversion efficiency of $1.5 \%$, representing a leap forward in improving the efficiency of photoanode for PEC water splitting.

\section{Results}

Structural and crystallographic properties. $\mathrm{Ba}-\mathrm{Ta}_{3} \mathrm{~N}_{5}$ nanorods were fabricated on a Ta foil by nitridation of $\mathrm{Ba}\left(\mathrm{NO}_{3}\right)_{2}$-loaded $\mathrm{Ta}_{2} \mathrm{O}_{5}$ nanorods grown by through-mask anodization. For comparison, undoped $\mathrm{Ta}_{3} \mathrm{~N}_{5}$ nanorods were fabricated by nitridation of $\mathrm{Ta}_{2} \mathrm{O}_{5}$ nanorods cut from the same sample without loading $\mathrm{Ba}\left(\mathrm{NO}_{3}\right)_{2}$. Figure 1 shows the structural and crystallographic properties of the $\mathrm{Ba}-\mathrm{Ta}_{3} \mathrm{~N}_{5}$ nanorods. The scanning electron microscopy (SEM) image in Fig. 1a reveals that the vertical alignment of the nanorods was retained after Ba doping. No obvious change in the morphology of the nanorods was found after Ba doping (Supplementary Fig. S1). The diameter and length of the $\mathrm{Ba}-\mathrm{Ta}_{3} \mathrm{~N}_{5}$ nanorods measured from the SEM image in Fig. $1 \mathrm{~b}$ were $\sim 60$ and $\sim 600 \mathrm{~nm}$, respectively. Using highly sensitive energy dispersive X-ray spectroscopy (EDS), Ba signal
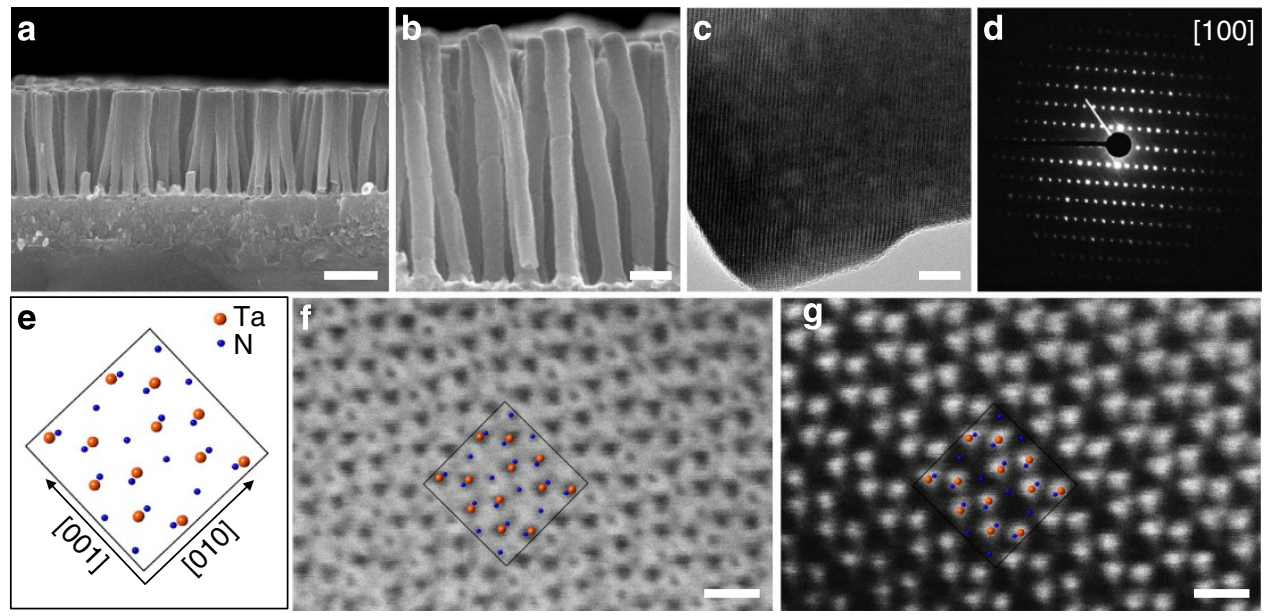

Figure 1 Structural properties of the $\mathbf{B a}-\mathbf{T a}_{\mathbf{3}} \mathbf{N}_{\mathbf{5}}$ nanorods. (a,b) SEM images of the cross-section of the vertically aligned $\mathrm{Ba}-\mathrm{Ta}_{3} \mathrm{~N}_{5}$ nanorod arrays. (c) High-resolution transmission electron microscopy image of a $\mathrm{Ba}-\mathrm{Ta}_{3} \mathrm{~N}_{5}$ nanorod, taken along the [100] zone axis. (d) Corresponding selected area electron diffraction pattern acquired from the nanorod in c. (e) Crystal structure of $\mathrm{Ba}-\mathrm{Ta}_{3} \mathrm{~N}_{5}$ viewed from the [100] crystallographic direction (from 3D-EDT data). (f) ABF and (g) HAADF scanning transmission electron microscopy images of a Ba- $\mathrm{Ta}_{3} \mathrm{~N}_{5}$ nanorod. Simulated cells of Ba-Ta $\mathrm{N}_{5}$ are overlaid in $\mathbf{f}$ and $\mathbf{g}$. Scale bars, (a) $300 \mathrm{~nm},(\mathbf{b}) 100 \mathrm{~nm},(\mathbf{c}) 10 \mathrm{~nm},(\mathbf{f}, \mathbf{g}) 0.5 \mathrm{~nm}$. 
was directly detected and the distribution of $\mathrm{Ba}$ on the surface of the sample was found to be uniform (Supplementary Fig. S2). From the cross-sectional EDS mapping, it was found that Ba was incorporated not only on the surface of the sample but also into the sample (Supplementary Fig. S3). The atomic concentration of $\mathrm{Ba}$ on the surface of the nanorods was estimated to be about $2.7 \%$ from X-ray photoelectron spectroscopy (XPS) spectra taken at a small take-off angle (20 ; Supplementary Figs S4 and S5). An atomic concentration of $0.6 \%$ was estimated by EDS (Supplementary Fig. S2). The difference between the XPS and EDS results suggests that the concentration of $\mathrm{Ba}$ on the surface may be higher than that in the bulk. The EDS and XPS results also revealed the existence of residual $\mathrm{O}$ in the nanorods. Using single crystal three-dimensional electron diffraction tomography (3D-EDT), both $\mathrm{Ta}_{3} \mathrm{~N}_{5}$ and Ba- $\mathrm{Ta}_{3} \mathrm{~N}_{5}$ nanorods have been found to have the same structure with space group symmetry $\mathrm{Cmcm}$ and unit cell parameters $a=3.62 \AA, b=10.04 \AA, c=9.86 \AA$. The detailed structure solutions for $\mathrm{Ta}_{3} \mathrm{~N}_{5}$ and $\mathrm{Ba}-\mathrm{Ta}_{3} \mathrm{~N}_{5}$ nanorods are given in Supplementary Figs S6-S9 and Supplementary Table S1. At present, unfortunately 3D-EDT without dynamical scattering data corrections does not have enough sensitivity to detect substitutional probability of $\mathrm{Ba}$ for $\mathrm{Ta}$ and $\mathrm{O}$ for $\mathrm{N}$. The high-resolution transmission electron microscopy image and the corresponding selected area electron diffraction pattern are shown in Fig. 1c,d. Both $\mathrm{Ta}_{3} \mathrm{~N}_{5}$ and $\mathrm{Ba}-\mathrm{Ta}_{3} \mathrm{~N}_{5}$ nanorods reveal high single-crystalline quality with the structure mentioned above. Using scanning transmission electron microscopy with aberration corrector in probe, annular bright field $(\mathrm{ABF})$ and high-angle annular dark field (HAADF) images of $\mathrm{Ba}^{-} \mathrm{Ta}_{3} \mathrm{~N}_{5}$ nanorods with atomic resolution were obtained. Figure $1 \mathrm{e}-\mathrm{g}$ show, respectively, the obtained crystal structure of $\mathrm{Ta}_{3} \mathrm{~N}_{5}$ projected along the [100], and corresponding $\mathrm{ABF}$ and HAADF images. High crystallinity and the structural consistency were confirmed. The HAADF image clearly shows the distribution of heaviest $\mathrm{Ta}$ and $\mathrm{Ba}$ elements. Although there is a clear different between the atomic numbers of both elements, the low Ba concentration and its random distribution into the Ta positions prevent its direct visualization from the contrast of the HAADF image. The complementary information about the location of the light elements was obtained from the simultaneously recorded $\mathrm{ABF}$ image, where atomic columns of $\mathrm{N}$ and $\mathrm{O}$ randomly distributed are clearly observed.

In addition to changing the properties of the nanorods, the doping of $\mathrm{Ba}$ also drastically changed the properties of the interlayer between the nanorods and Ta substrate (Fig. 1a). This interlayer is grown simultaneously with the nanorods in the through-mask anodization process and its composition is a key factor affecting the activity of the nanorod photoanode. In our previous report ${ }^{15}$, we demonstrated that the interlayer was transformed into $\mathrm{Ta}_{5} \mathrm{~N}_{6} / \mathrm{Ta}_{2} \mathrm{~N}$ by using high-temperature nitridation, which enhanced the activity of the nanorod photoanode. The activity of the nanorod photoanode could be further improved if the less conductive $\mathrm{Ta}_{5} \mathrm{~N}_{6}$ phase is suppressed. It is therefore of particular interest to discover that the doping of $\mathrm{Ba}$ greatly suppressed the $\mathrm{Ta}_{5} \mathrm{~N}_{6}$ phase in the interlayer. As shown in Fig. 2, the intensity of $\mathrm{Ta}_{5} \mathrm{~N}_{6}$ peaks in the $\mathrm{X}$-ray diffraction $(\mathrm{XRD})$ pattern of the Ba-doped sample was much reduced compared with that for the undoped sample. As a result, the conductivity of the Ba-doped interlayer, which mainly consisted of $\mathrm{Ta}_{2} \mathrm{~N}$, was enhanced by approximately three times compared with that of the undoped interlayer, which consisted of $\mathrm{Ta}_{5} \mathrm{~N}_{6}$ and $\mathrm{Ta}_{2} \mathrm{~N}$ (Supplementary Fig. S10).

Co-catalyst modification. The coupling of an efficient light absorber with an active electrocatalysts is essential to make highly

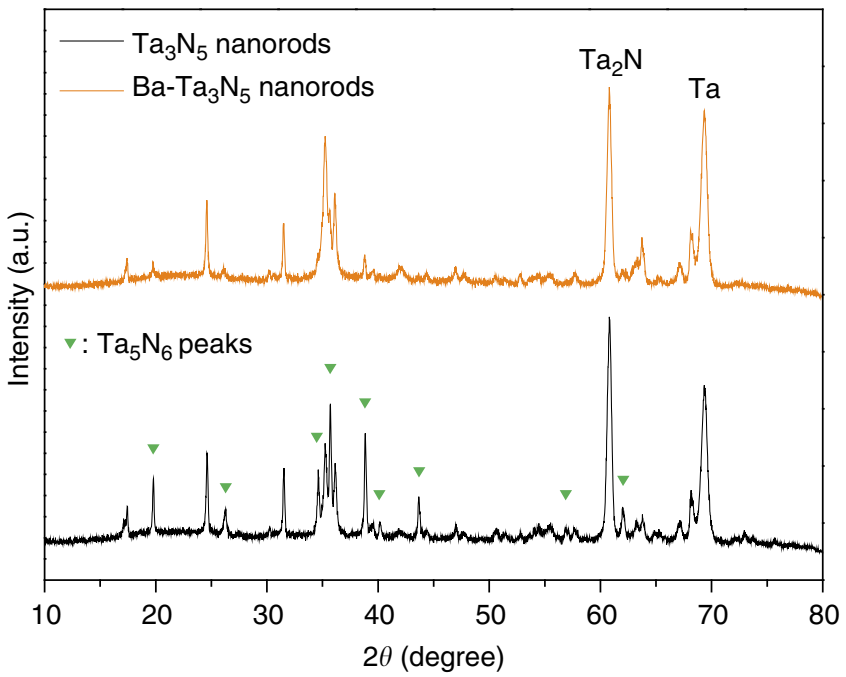

Figure 2 | XRD patterns for $\mathbf{T a}_{\mathbf{3}} \mathbf{N}_{\mathbf{5}}$ and $\mathbf{B a}-\mathbf{T a}_{\mathbf{3}} \mathbf{N}_{\mathbf{5}}$ nanorods. The diffraction peaks for the $\mathrm{Ta}_{5} \mathrm{~N}_{6}$ phase in the undoped sample are indicated by the green triangles. The $\mathrm{Ta}_{5} \mathrm{~N}_{6}$ phase in the interlayer was greatly suppressed by Ba doping.

efficient photoelectrodes for water splitting. Especially for the photoanode, modifying the surface with an appropriate oxygen evolution electrocatalyst (co-catalyst) has an important role in lowering the overpotential and stabilizing the surface. The Co-Pi oxygen-evolving complex has, since its discovery ${ }^{32}$, raised wide interest in the water-splitting field, and has been used to modify various photoanodes to improve their activity and stability $20,21,33-36$. In our work, Co-Pi was employed as a cocatalyst for the $\mathrm{Ba}-\mathrm{Ta}_{3} \mathrm{~N}_{5}$ nanorod photoanode. Without modifying Co-Pi, the nanorod photoanodes showed poor activity and stability (Supplementary Fig. S11). The Co-Pi cocatalyst was deposited on the nanorod surface by photo-assisted electrodeposition in constant current mode at a small current density (Supplementary Fig. S12). The deposition of Co-Pi under a small current density is believed to be beneficial to the formation of a uniform Co-Pi coating on the nanorods. The amount of the Co-Pi deposited on the surface of the sample was optimized to achieve both high activity and stability (Supplementary Fig. S13).

PEC water-splitting properties. The PEC water-splitting properties of the $\mathrm{Co}-\mathrm{Pi} / \mathrm{Ba}-\mathrm{Ta}_{3} \mathrm{~N}_{5}$ nanorod photoanode are given in Fig. 3. The PEC properties of the $\mathrm{Co}-\mathrm{Pi} / \mathrm{Ta}_{3} \mathrm{~N}_{5}$ nanorod photoanode are also given for comparison. Figure 3a shows the current-potential curves for the two electrodes in the dark and under air mass (AM) 1.5G-simulated sunlight. In the dark, both electrodes show negligible current. Under AM 1.5G, the photocurrent onset (measured at $0.2 \mathrm{~mA} \mathrm{~cm}^{-2}$ according to ref. 36) of the Ba-doped nanorod photoanode is at $0.65 \mathrm{~V}$ versus reversible hydrogen electrode (RHE), which shifts $\sim 50 \mathrm{mV}$ cathodically relative to the undoped sample. The sharp rise beyond the onset potential and the tendency for photocurrent saturation in the high-potential region indicate high-charge transfer and collection efficiency in the $\mathrm{Co}-\mathrm{Pi} / \mathrm{Ba}-\mathrm{Ta}_{3} \mathrm{~N}_{5}$ nanorods. The photocurrent density of the $\mathrm{Co}-\mathrm{Pi} / \mathrm{Ba}-\mathrm{Ta}_{3} \mathrm{~N}_{5}$ nanorod photoanode reaches $6.7 \mathrm{~mA} \mathrm{~cm}^{-2}$ at the water oxidation potential $(1.23 \mathrm{~V}$ versus RHE). More importantly, high photocurrent density is achieved in the lower applied potential region. In the potential range of 0.7-1 V versus RHE, the photocurrent density in the Ba-doped sample is $1-5.5 \mathrm{~mA} \mathrm{~cm}^{-2}$, which represents an increase of $50-300 \%$ compared with the undoped sample. Figure $3 \mathrm{~b}$ plots the 

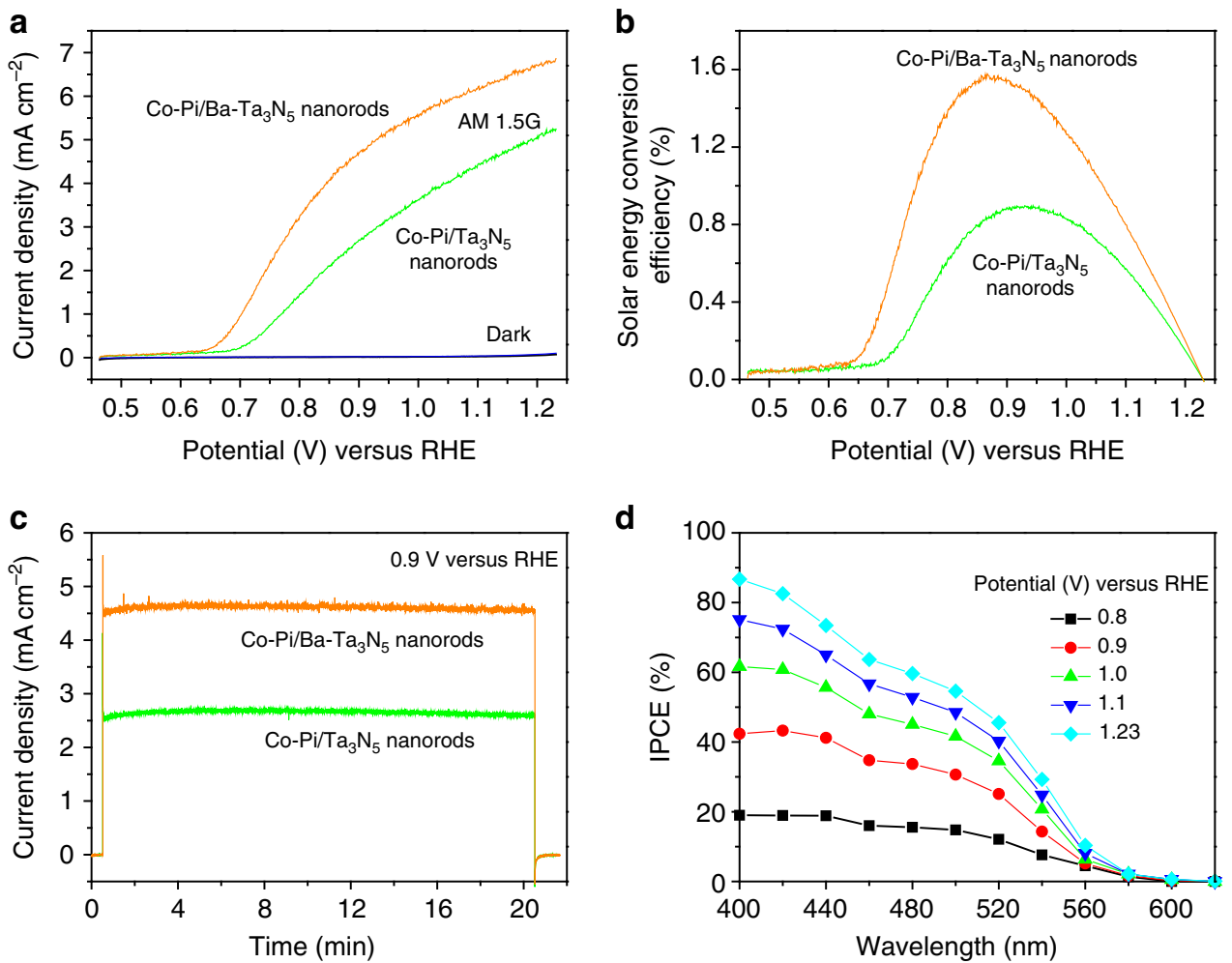

Figure 3 | Solar-driven PEC water-splitting properties. (a) Current-potential curves for Co- $\mathrm{Pi} / \mathrm{Ta}_{3} \mathrm{~N}_{5}$ nanorod photoanode and Co-Pi/Ba-Ta $\mathrm{N}_{5}$ nanorod photoanode in dark and under AM 1.5G-simulated sunlight. (b) Solar energy conversion efficiency of the photoanodes calculated from the currentpotential curves in a. (c) Steady-state photocurrent of the photoanodes held at $0.9 \mathrm{~V}$ versus RHE under AM 1.5G-simulated sunlight. (d) Wavelength dependence of IPCE for $\mathrm{Co}-\mathrm{Pi} / \mathrm{Ba}-\mathrm{Ta}_{3} \mathrm{~N}_{5}$ nanorod photoanode at different applied potentials.

solar energy conversion efficiency of the two photoanodes calculated from the current-potential curves in Fig. 3a. The solar energy conversion efficiency is above $1 \%$ in the potential range of 0.75-1.05 V versus RHE for the Co- $\mathrm{Pi} / \mathrm{Ba}-\mathrm{Ta}_{3} \mathrm{~N}_{5}$ nanorod photoanode. A maximum conversion efficiency of $1.56 \%$ is achieved at $0.87 \mathrm{~V}$ versus $\mathrm{RHE}$, as compared with the $0.89 \%$ at $0.93 \mathrm{~V}$ versus RHE for the undoped sample. It should be noted that the efficiency of the undoped $\mathrm{Ta}_{3} \mathrm{~N}_{5}$ nanorod photoanode is also much enhanced compared with our previous report (ref. 15) owing to the improved co-catalyst modification method. Nanorods with different diameters and densities have been tested, which showed that the nanorods used above gave the highest efficiency (Supplementary Fig. S14 and Supplementary Table S2).

Figure $3 \mathrm{c}$ shows the steady-state photocurrent of the photoanodes measured at $0.9 \mathrm{~V}$ versus RHE under AM 1.5G. It was found that the steady-state photocurrent densities were equal to the photocurrent densities of the current-potential curves in Fig. 3a, thus confirming that the conversion efficiency calculated from the current-potential curves represent steady-state behaviour. Both samples showed a stable photocurrent for $20 \mathrm{~min}$, demonstrating that the Co-Pi co-catalyst modified using our method was effective in preventing self-oxidation of the $\mathrm{Ta}_{3} \mathrm{~N}_{5}$ and $\mathrm{Ba}-\mathrm{Ta}_{3} \mathrm{~N}_{5}$ nanorods. Recently, there has been some debate about whether Co-Pi acts as a catalyst or spectator ${ }^{36-38}$. We believe that in our case the Co-Pi functions as a catalyst because otherwise self-oxidation would result if the water oxidation occurred on the $\mathrm{Ta}_{3} \mathrm{~N}_{5}$ or $\mathrm{Ba}-\mathrm{Ta}_{3} \mathrm{~N}_{5}$ sites. Figure $3 \mathrm{~d}$ plots the wavelength dependence of the incident photon-to-current conversion efficiency (IPCE) for the $\mathrm{Co}-\mathrm{Pi} / \mathrm{Ba}-\mathrm{Ta}_{3} \mathrm{~N}_{5}$ nanorod photoanode measured at different applied potentials (see Supplementary Fig. S15). The Tauc plots of the IPCE spectra in
Supplementary Fig. S16 reveals that the band gap of the $\mathrm{Ba}-\mathrm{Ta}_{3} \mathrm{~N}_{5}$ nanorods is $\sim 2.1 \mathrm{eV}$, same as that of undoped $\mathrm{Ta}_{3} \mathrm{~N}_{5}$. At the water oxidation potential (that is, $1.23 \mathrm{~V}$ versus RHE, where the IPCEs of different photoanodes are usually compared), the IPCEs are $55-86 \%$ in the $500-400 \mathrm{~nm}$ range. Even at lower applied potentials, the IPCEs are quite high in this range. The relatively low IPCEs above $500 \mathrm{~nm}$ indicate the possibility of further improving the overall efficiency of the photoanode by enhancing the efficiencies in this region of spectrum. By integrating the IPCE spectrum measured at $1.23 \mathrm{~V}$ versus RHE in Fig. 3d over the spectrum of the AM 1.5G (ASTM G173-03), a photocurrent density of $\sim 6.3 \mathrm{~mA} \mathrm{~cm}^{-2}$ was estimated, which was close to that of $\sim 6.7 \mathrm{~mA} \mathrm{~cm}^{-2}$ measured from the current-potential curve in Fig. 3a (Supplementary Fig. S17). This demonstrates that the current-potential curves measured using our solar simulator and the IPCE data are of good accuracy.

To confirm that the reactions taking place on the $\mathrm{Co}-\mathrm{Pi} / \mathrm{Ba}$ $\mathrm{Ta}_{3} \mathrm{~N}_{5}$ nanorod photoanode and the Pt counter electrode are the oxygen evolution reaction (OER) and hydrogen evolution reaction (HER), respectively, the gases evolved from both electrodes were quantified by gas chromatography (Fig. 4). The $\mathrm{Co}-\mathrm{Pi} / \mathrm{Ba}-\mathrm{Ta}_{3} \mathrm{~N}_{5}$ nanorod photoanode was held at $0.9 \mathrm{~V}$ versus RHE under AM $1.5 \mathrm{G}$ for $100 \mathrm{~min}$. The amount of electrons passing through the outer circuit was $265 \mu \mathrm{mol} \mathrm{cm}{ }^{-2}$ during the $100 \mathrm{~min}$. The amounts of $\mathrm{O}_{2}$ and $\mathrm{H}_{2}$ evolved from the $\mathrm{Co}-\mathrm{Pi} / \mathrm{Ba}$ $\mathrm{Ta}_{3} \mathrm{~N}_{5}$ nanorod photoanode and the $\mathrm{Pt}$ counter electrode were 63.5 and $130 \mu \mathrm{mol} \mathrm{cm}-2$, respectively. The ratio of evolved $\mathrm{O}_{2}$ and $\mathrm{H}_{2}$ is close to stoichiometry, and the Faraday efficiencies of the OER and HER are $96 \%$ and $98 \%$, respectively. These results suggest that the photocurrent is indeed due to the OER and HER and the conversion efficiency calculated from the photocurrent does represent the solar-to-hydrogen conversion efficiency of the 


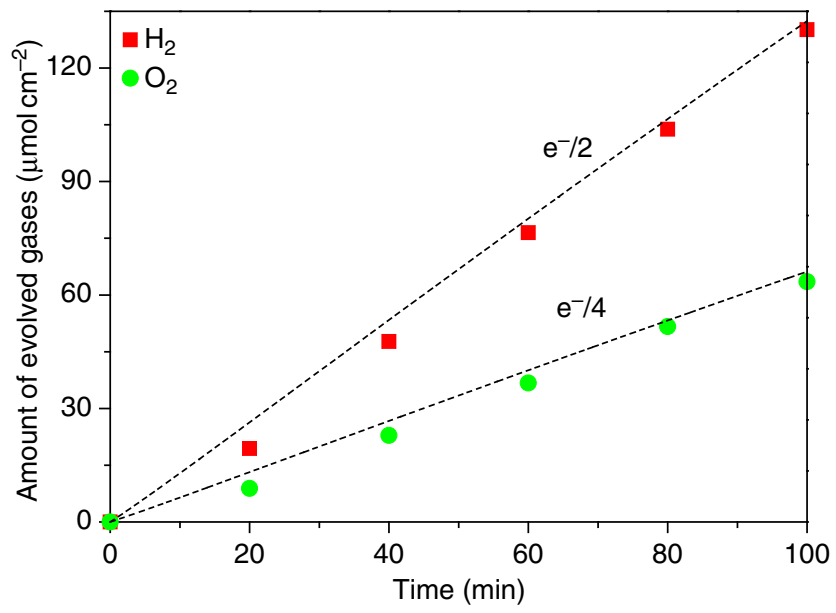

Figure 4 | Gas chromatography of the oxygen and hydrogen evolved from the electrodes. The photoanode was biased at $0.9 \mathrm{~V}$ versus RHE. The dashed lines indicate the expected amount of oxygen and hydrogen evolution with unity Faraday efficiency.

photoanode. The results also demonstrate that the photoanode has good stability for the OER. The photocurrent decayed by only 5\% after 100 min (Supplementary Fig. S18).

\section{Discussion}

To exclude the effect of nitrate ions $\left(\mathrm{NO}_{3}^{-}\right)$on enhancing the PEC activity of $\mathrm{Ta}_{3} \mathrm{~N}_{5}$ nanorods, different nitrate precursors including $\mathrm{NaNO}_{3}, \mathrm{Mg}\left(\mathrm{NO}_{3}\right)_{2}$ and $\mathrm{Al}\left(\mathrm{NO}_{3}\right)_{3}$ were used to treat the sample under the same process as that for the $\mathrm{Ba}\left(\mathrm{NO}_{3}\right)_{2}$ precursor. The concentrations of $\mathrm{NO}_{3}^{-}$in the aqueous solutions were kept at $0.2 \mathrm{M}$ for all nitrate precursors. As shown in Supplementary Fig. S19, the suppression of $\mathrm{Ta}_{5} \mathrm{~N}_{6}$ phase was only found in the $\mathrm{Ba}\left(\mathrm{NO}_{3}\right)_{2}$-treated sample. Compared with undoped sample in Fig. 3a, the $\mathrm{NaNO}_{3}$ - and $\mathrm{Mg}\left(\mathrm{NO}_{3}\right)_{2}$-treated samples showed even lower activity, whereas the $\mathrm{Al}\left(\mathrm{NO}_{3}\right)_{3}$-treated sample showed only slightly enhanced activity, not comparable to the $\mathrm{Ba}\left(\mathrm{NO}_{3}\right)_{2}$-treated sample. The effect of $\mathrm{Ba}$ doping on enhancing the PEC activity of the $\mathrm{Ta}_{3} \mathrm{~N}_{5}$ nanorods was further demonstrated by treating the sample with different $\mathrm{Ba}$ precursors. Aqueous solutions of $\mathrm{Ba}\left(\mathrm{NO}_{3}\right)_{2}$, barium chloride and barium acetate with the same concentration $(0.1 \mathrm{M})$ were used as Ba precursors to treat the samples under the same condition. As shown in Supplementary Fig. S20, the suppression of $\mathrm{Ta}_{5} \mathrm{~N}_{6}$ phase was found in all the samples treated with these Ba precursors. All the samples showed similar PEC activity, which were much enhanced compared with that of the undoped sample in Fig. 3a. The above results excluded the effect of $\mathrm{NO}_{3}^{-}$and confirmed the effect of $\mathrm{Ba}$ on enhancing the PEC activity of $\mathrm{Ta}_{3} \mathrm{~N}_{5}$ nanorods. The concentration of the $\mathrm{Ba}\left(\mathrm{NO}_{3}\right)_{2}$ precursor was also optimized, which was found to be $0.1 \mathrm{M}$ (Supplementary Fig. S21).

The enhancing effect of Ba doping on PEC activity of the $\mathrm{Ta}_{3} \mathrm{~N}_{5}$ nanorod photoanode is ascribed to the enhanced electrical conductivity of the interlayer and the improved surface and bulk properties of the nanorods for water splitting. The enhanced conductivity of the interlayer was achieved by suppressing the $\mathrm{Ta}_{5} \mathrm{~N}_{6}$ phase in the interlayer, which allowed the electrons to be collected more efficiently at the back contact. The doping of $\mathrm{Ba}$ could improve the properties of the $\mathrm{Ta}_{3} \mathrm{~N}_{5}$ nanorods for water splitting in two aspects. First, the surface hydroxyl concentration of the nanorod is increased because $\mathrm{Ba}$ on the surface easily bonds with hydroxyl ions in the electrolyte. The adsorption of these potential-determining ions on the nanorod surface could change the interfacial energetics and shift the flatband potential ${ }^{18}$. Indeed, a Mott-Schottky analysis (Supplementary Fig. S22) showed that the flatband potential of the $\mathrm{Ba}-\mathrm{Ta}_{3} \mathrm{~N}_{5}$ nanorods shifted cathodically by $90 \mathrm{mV}$ relative to that of the undoped $\mathrm{Ta}_{3} \mathrm{~N}_{5}$ nanorods. The cathodic shift of the flatband potential could contribute to the shift of the onset potential of the current-potential curves and improved PEC activity observed in Fig. 3a. A similar enhancing effect of $\mathrm{Ba}$ doping on the photocatalytic water-splitting activity of $\mathrm{La}_{2} \mathrm{Ti}_{2} \mathrm{O}_{7}$ because of increased surface hydroxyl concentration has been reported ${ }^{39}$. The results suggest a way to improve the efficiency of the photoelectrode by controlling the potential-determining ions. Second, the carrier density in the nanorod was increased by $>50 \%$ after doping with Ba (Supplementary Fig. S22). The increased carrier density could lead to more efficient electron transfer in the nanorods. As a consequence of the synergistic effects of enhanced interlayer conductivity, cathodically shifted flatband potential, and increased electron density in the nanorods, the PEC activity of the $\mathrm{Ta}_{3} \mathrm{~N}_{5}$ nanorod photoanode was improved after $\mathrm{Ba}$ doping.

In conclusion, we demonstrated an efficient and stable photoanode for water splitting by coupling an intentionally doped semiconductor nanostructure (that is, $\mathrm{Ba}-\mathrm{Ta}_{3} \mathrm{~N}_{5}$ nanorod) with a stable OER co-catalyst (that is, Co- $\mathrm{Pi}$ ). The $\mathrm{Co}-\mathrm{Pi} / \mathrm{Ba}-\mathrm{Ta}_{3} \mathrm{~N}_{5}$ nanorod photoanode yielded a maximum solar energy conversion efficiency of $1.5 \%$. To our knowledge, this is more than three times higher than the current state-of-the-art solar energy conversion efficiency of single-photon photoanodes for PEC water splitting. Further, stoichiometric $\mathrm{O}_{2}$ and $\mathrm{H}_{2}$ were stably produced on the $\mathrm{Co}-\mathrm{Pi} / \mathrm{Ba}-\mathrm{Ta}_{3} \mathrm{~N}_{5}$ nanorod photoanode and the Pt counter electrode with Faraday efficiency of almost unity. This represents a leap forward in pursuing the 10\% solar-to-fuel conversion efficiency goal and further efforts are being made to shift the photocurrent onset, boost the efficiency at longer wavelengths, as well as improve the long-term stability.

\section{Methods}

Preparation of nanorod photoelectrodes. Vertically aligned $\mathrm{Ta}_{2} \mathrm{O}_{5}$ nanorods were grown on a Ta foil $\left(0.1 \mathrm{~mm}\right.$ in thickness, $1 \times 5 \mathrm{~cm}^{2}$ in size) by through-mask anodization. A Ta foil $(99.95 \%$, Nilaco) with a thickness of $0.1 \mathrm{~mm}$ was cut into $1 \times 5 \mathrm{~cm}^{2}$ pieces and cleaned in acetone and isopropyl alcohol. An Al layer with a thickness of $\sim 2 \mu \mathrm{m}$ was deposited on the Ta substrate by thermal evaporation. The Al layer was anodized in $0.3 \mathrm{M}$ oxalic acid at $40 \mathrm{~V}$ for $2 \mathrm{~h}$ to form a porous anodic alumina (PAA) mask. Subsequently, the nanochannels of the PAA mask were widened by dipping into a $5 \% \mathrm{H}_{3} \mathrm{PO}_{4}$ aqueous solution at $60^{\circ} \mathrm{C}$ for $90 \mathrm{~s}$. The masked Ta substrates were then anodized in a $0.5-\mathrm{M} \mathrm{H}_{3} \mathrm{BO}_{3}$ aqueous solution at room temperature under stirring. The anodizing voltage was ramped from 0 to $650 \mathrm{~V}$ at a rate of $0.1 \mathrm{~V} \mathrm{~s}^{-1}$ and held at $650 \mathrm{~V}$ for $1 \mathrm{~h}$. The $\mathrm{Ta}_{2} \mathrm{O}_{5}$ nanorods embedded into the PAA mask were released by selectively etching away the PAA mask with a $5 \% \mathrm{H}_{3} \mathrm{PO}_{4}$ aqueous solution at $60{ }^{\circ} \mathrm{C}$ for $4 \mathrm{~h}$. The obtained $\mathrm{Ta}_{2} \mathrm{O}_{5}$ nanorod array was further cut into $5 \times 10 \mathrm{~mm}^{2}$ pieces. The Ba precursor was introduced by dipping the $\mathrm{Ta}_{2} \mathrm{O}_{5}$ nanorods into an aqueous solution of $0.1 \mathrm{M}$ $\mathrm{Ba}\left(\mathrm{NO}_{3}\right)_{2}$ for $\sim 10 \mathrm{~s}$ and dried with a $\mathrm{N}_{2}$ gun. $\mathrm{Ba}-\mathrm{Ta}_{3} \mathrm{~N}_{5}$ nanorods and $\mathrm{Ta}_{3} \mathrm{~N}_{5}$ nanorods were obtained by nitridation of $\mathrm{Ta}_{2} \mathrm{O}_{5}$ nanorods with and without $\mathrm{Ba}$ in a horizontal tube furnace under $5 \mathrm{sccm} \mathrm{NH} \mathrm{N}_{3}$ flow at $1,000^{\circ} \mathrm{C}$ for $2 \mathrm{~h}$. Electrical contact was established by embedding a $\mathrm{Cu}$ wire in a eutectic gallium-indium alloy (Aldrich) that contacted the bottom Ta layer of the sample. The $\mathrm{Cu}$ wire and the eutectic were covered with Kapton tape (Nitto Tape) and then encapsulated with epoxy (Araldite). The exposed area of the electrode after packaging was about $0.4 \mathrm{~cm}^{2}$.

Photo-assisted electrodeposition of Co-Pi co-catalyst. Before Co-Pi deposition, the electrode was immersed in a mixed etchant of $\mathrm{HF}: \mathrm{HNO}_{3}: \mathrm{H}_{2} \mathrm{O}(1: 2: 7 \mathrm{in} \mathrm{v} / \mathrm{v})$ for $10 \mathrm{~s}$ and rinsed with pure water. The freshly prepared electrode was transferred to a three-electrode PEC cell for photo-assisted electrodeposition of the Co-Pi co-catalyst. The nanorod electrode was used as the working electrode, $\mathrm{Ag} / \mathrm{AgCl}$ as the reference electrode and a Pt wire as the counter electrode. The Co-Pi cocatalyst was deposited in a stirred solution of $0.5 \mathrm{mM} \mathrm{Co}\left(\mathrm{NO}_{3}\right)_{2}$ in $0.1 \mathrm{M}$ potassium phosphate buffer at pH 7 at a constant current density of $10 \mu \mathrm{Acm}^{-2}$ over a period of $8 \mathrm{~min}$ under AM 1.5G-simulated sunlight. After deposition, the electrode was rinsed with pure water. 
Structural characterization. SEM images of the nanorods were taken with a Hitachi S- 4700 at an accelerating voltage of $20 \mathrm{kV}$. XRD patterns of the samples were measured with a Rigaku Ultima III using $\mathrm{Cu} \mathrm{K}_{\alpha}$ radiation at $40 \mathrm{kV}$ and $40 \mathrm{~mA}$. XPS spectra were measured with a JEOL JPS-9010 using non-chromatic $\mathrm{Al}$ $\mathrm{K}_{\alpha}$ radiation at $12 \mathrm{kV}$ and $25 \mathrm{~mA}$. The electron analyser was operated at pass energies of $50 \mathrm{eV}$ for wide scan and $10 \mathrm{eV}$ for narrow scan, which gave full width at half maximum of 1.8 and $0.9 \mathrm{eV}$ for the $\mathrm{Ag} 3 \mathrm{~d}_{5 / 2}$ peak, respectively. XPS spectra were measured at take-off angles of $90^{\circ}$ and $20^{\circ}$. The peak shift due to charging was corrected using the $\mathrm{C} 1$ s peak at $285 \mathrm{eV}$ as an internal standard. Quantitative XPS analysis was done using a relative sensitivity factor method. High-resolution transmission electron microscopy images, selected area electron diffraction patterns and 3D-EDT were recorded on a JEOL $2100\left(\mathrm{LaB}_{6}\right.$ filament $)$ with $\mathrm{Cs}=1.4$ $\mathrm{mm}$ operated at $200 \mathrm{kV}$. Samples were prepared by scratching nanorods on a filter paper using tweezers, and then a copper grid was put on to stick some nanorods. After that, the TEM grid was heated for $2 \mathrm{~h}$ under lamp. Diffraction patterns in 3D reciprocal space were collected in accessible angular range by combination of electron-beam tilt and sample-holder tilt with a designated step. Herein the total range of angles covered for both samples are over $120^{\circ}$ with $0.1 \times$ step. HAADF and $\mathrm{ABF}$ scanning transmission electron microscopy images were acquired with a JEOL JEM-ARM200F equipped with a Cs-aberration corrector in condenser lens operated at $200 \mathrm{kV}$ provided with a spherical aberration corrector in probe (current emission density $\sim 1.4 \times 10^{-9} \mathrm{~A}$ and probe size $\sim 0.8 \mathrm{~A}$ ), a GIF-QuantumER spectrometer and Oxford INCA-350 detector. Solid semiangles between 68-280 mrad and 11-22 mrad were used for acquisition of HAADF and ABF images, respectively ( $38 \mathrm{~s}$ per frame). EDS spectra and elemental maps were taken with a JEOL JSM-7800F equipped with a highly sensitive silicon drift detector (Oxford Instruments, X-Max ${ }^{\mathrm{N}} 150$ ) at an effective solid angle of $0.042 \mathrm{sr}$ and an accelerating voltage of $8 \mathrm{kV}$.

PEC measurements. PEC water-splitting properties of the nanorod photoelectrodes were measured with the three-electrode configuration using an $\mathrm{Ag} / \mathrm{AgCl}$ reference electrode and a Pt wire counter electrode. The potential of the working electrode was controlled by a potentiostat (Hokuto Denko, HSV-100). The measured potential versus $\mathrm{Ag} / \mathrm{AgCl}$ was converted to the RHE scale according to the Nernst equation $\left(E_{\mathrm{RHE}}=E_{\mathrm{Ag} / \mathrm{AgCl}}+0.059 \mathrm{pH}+0.197\right)$. An aqueous solution of $0.5 \mathrm{M} \mathrm{K}_{2} \mathrm{HPO}_{4}$ was used as the electrolyte. The $\mathrm{pH}$ of the electrolyte was adjusted to 13 by adding $\mathrm{KOH}$. The electrolyte was stirred and purged with Ar gas before the measurements. The photoelectrodes were illuminated with AM 1.5G-simulated sunlight at $100 \mathrm{~mW} \mathrm{~cm}^{-2}$ from a commercial solar simulator (SAN-EI Electric, XES-301 S). Current-potential curves were measured at a scan rate of $10 \mathrm{mV} \mathrm{s}^{-1}$ from negative to positive. Solar energy conversion efficiency $(\eta)$ of the photoanode (defined in ref. 6 for an individual photoelectrode) was calculated from the current-potential curves measured in the dark and under AM $1.5 \mathrm{G}$ with the equation $\left.\eta=\left[1.23-V_{\text {app }}\right) \times\left(J_{\text {light }}-J_{\text {dark }}\right) / P_{\text {light }}\right] \times 100 \%$, where $V_{\text {app }}$ is the applied potential versus RHE, $J_{\text {dark }}$ and $J_{\text {light }}$ are the respective current densities in the dark and under AM $1.5 \mathrm{G}$ and $P_{\text {light }}$ is the power density of AM $1.5 \mathrm{G}\left(100 \mathrm{~mW} \mathrm{~cm}^{-2}\right)$. The wavelength dependence of IPCE was measured under monochromatic irradiation from a Xe lamp (Asahi Spectra, MAX-302) equipped with bandpass filters (central wavelengths: $400-620 \mathrm{~nm}$, every $20 \mathrm{~nm}$; full width at half maximum: $10 \mathrm{~nm}$ ). The irradiance spectra of the light incident on the electrode surface were measured with a spectroradiometer (EKO Instruments, LS-100). The IPCE at each wavelength $(\lambda)$ was calculated via the equation IPCE $=\left[(1240 / \lambda) \times\left(J_{\text {light }}-J_{\text {dark }}\right) /\right.$ $\left.P_{\text {light }}\right] \times 100 \%$.

Gas chromatography. An air-tight three-electrode PEC cell with an $\mathrm{Ag} / \mathrm{AgCl}$ reference electrode and a Pt wire counter electrode was used for gas chromatography. The PEC cell was connected to a vacuum pump and a gas chromatograph. Before measurement, the PEC cell was pumped to a base pressure of a few Torr (because of the vapour pressure of water) and then backfilled with Ar to about 40 Torr. The $\mathrm{Co}-\mathrm{Pi} / \mathrm{Ba}-\mathrm{Ta}_{3} \mathrm{~N}_{5}$ nanorod photoelectrode was biased at $0.9 \mathrm{~V}$ versus RHE in a stirred aqueous solution of $0.5 \mathrm{M} \mathrm{K}_{2} \mathrm{HPO}_{4}(\mathrm{pH}=13)$ under AM $1.5 \mathrm{G}-$ simulated sunlight. The amount of oxygen and hydrogen evolved from the photoelectrode and the Pt counter electrode were measured with a gas chromatograph (Shimadzu, GC-8A).

\section{References}

1. Dahl, S. \& Chorkendorff, I. Solar-fuel generation: towards practical implementation. Nat. Mater. 11, 100-101 (2012).

2. Lewis, N. S. Toward cost-effective solar energy use. Science 315, 798-801 (2007).

3. Blankenship, R. E. et al. Comparing photosynthetic and photovoltaic efficiencies and recognizing the potential for improvement. Science 332, 805-809 (2011).

4. Fujishima, A. \& Honda, K. Electrochemical photolysis of water at a semiconductor electrode. Nature 238, 37-38 (1972).

5. Gratzel, M. Photoelectrochemical cells. Nature 414, 338-344 (2001).

6. Walter, M. G. et al. Solar water splitting cells. Chem. Rev. 110, 6446-6473 (2010)
7. Khaselev, O. \& Turner, J. A. A monolithic photovoltaic-photoelectrochemical device for hydrogen production via water splitting. Science 280, 425-427 (1998).

8. Hou, Y. et al. Bioinspired molecular co-catalysts bonded to a silicon photocathode for solar hydrogen evolution. Nat. Mater. 10, 434-438 (2011).

9. Paracchino, A. et al. Highly active oxide photocathode for photoelectrochemical water reduction. Nat. Mater. 10, 456-461 (2011).

10. Moriya, M. et al. Stable hydrogen evolution from CdS modified $\mathrm{CuGaSe}_{2}$ photoelectrode under visible light irradiation. J. Am. Chem. Soc. 135, 3733-3735 (2013).

11. Seger, B. et al. Using $\mathrm{TiO}_{2}$ as a conductive protective layer for photocathodic $\mathrm{H}_{2}$ evolution. J. Am. Chem. Soc. 135, 1057-1064 (2013).

12. Boettcher, S. W. et al. Photoelectrochemical hydrogen evolution using Si microwire arrays. J. Am. Chem. Soc. 133, 1216-1219 (2011).

13. Tilley, S. D. et al. Light-induced water splitting with hematite: improved nanostructure and iridium oxide catalysis. Angew. Chem. Int. Ed. 49, 6405-6408 (2010).

14. Sivula, K., Le Formal, F. \& Gratzel, M. Solar water splitting: progress using hematite $\alpha-\mathrm{Fe}_{2} \mathrm{O}_{3}$ photoelectrodes. ChemSusChem 4, 432-449 (2011).

15. Li, Y. et al. Vertically aligned $\mathrm{Ta}_{3} \mathrm{~N}_{5}$ nanorod arrays for solar-driven photoelectrochemical water splitting. Adv. Mater. 25, 125-131 (2013).

16. Minegishi, T. et al. Photoelectrochemical properties of $\mathrm{LaTiO}_{2} \mathrm{~N}$ electrodes prepared by particle transfer for sunlight-driven water splitting. Chem. Sci. 4, 1120-1124 (2013).

17. Higashi, M., Domen, K. \& Abe, R. Highly stable water splitting on oxynitride TaON photoanode system under visible light irradiation. J. Am. Chem. Soc. 134, 6968-6971 (2012)

18. Osterloh, F. E. Inorganic nanostructures for photoelectrochemical and photocatalytic water splitting. Chem. Soc. Rev. 42, 2294-2320 (2013).

19. Chun, W.-J. et al. Conduction and valence band bositions of $\mathrm{Ta}_{2} \mathrm{O}_{5}, \mathrm{TaON}$, and $\mathrm{Ta}_{3} \mathrm{~N}_{5}$ by UPS and electrochemical methods. J. Phys. Chem. B 107, 1798-1803 (2003).

20. Seabold, J. A. \& Choi, K.-S. Effect of a cobalt-based oxygen evolution catalyst on the stability and the selectivity of photo-oxidation reactions of a $\mathrm{WO}_{3}$ photoanode. Chem. Mater. 23, 1105-1112 (2011).

21. Pilli, S. K. et al. Cobalt-phosphate (Co-Pi) catalyst modified Mo-doped $\mathrm{BiVO}_{4}$ photoelectrodes for solar water oxidation. Energ. Environ. Sci. 4, 5028-5034 (2011).

22. Hisatomi, T. et al. Preparation of crystallized mesoporous $\mathrm{Ta}_{3} \mathrm{~N}_{5}$ assisted by chemical vapor deposition of tetramethyl orthosilicate. Chem. Mater. 22, 3854-3861 (2010).

23. Tabata, M. et al. Modified $\mathrm{Ta}_{3} \mathrm{~N}_{5}$ powder as a photocatalyst for $\mathrm{O}_{2}$ evolution in a two-step water splitting system with an iodate/iodide shuttle redox mediator under visible light. Langmuir 26, 9161-9165 (2010).

24. Yokoyama, D. et al. $\mathrm{Ta}_{3} \mathrm{~N}_{5}$ photoanodes for water splitting prepared by sputtering. Thin Solid Films 519, 2087-2092 (2011).

25. Feng, X. et al. $\mathrm{Ta}_{3} \mathrm{~N}_{5}$ nanotube arrays for visible light water photoelectrolysis. Nano Lett. 10, 948-952 (2010).

26. Liao, M. et al. $\mathrm{Co}_{3} \mathrm{O}_{4}$ Nanoparticles as robust water oxidation catalysts towards remarkably enhanced photostability of a $\mathrm{Ta}_{3} \mathrm{~N}_{5}$ photoanode. Adv. Func. Mater. 22, 3066-3074 (2012).

27. Higashi, M., Domen, K. \& Abe, R. Fabrication of efficient $\mathrm{TaON}$ and $\mathrm{Ta}_{3} \mathrm{~N}_{5}$ photoanodes for water splitting under visible light irradiation. Energ. Environ. Sci. 4, 4138-4147 (2011).

28. Cong, Y. et al. Synthesis of $\mathrm{Ta}_{3} \mathrm{~N}_{5}$ nanotube arrays modified with electrocatalysts for photoelectrochemical water oxidation. J. Phys. Chem. C 116, 14541-14550 (2012).

29. Ma, S. S. et al. Enhanced water oxidation on $\mathrm{Ta}_{3} \mathrm{~N}_{5}$ photocatalysts by modification with alkaline metal salts. J. Am. Chem. Soc. 134, 19993-19996 (2012).

30. Kado, Y. et al. Strongly enhanced photocurrent response for $\mathrm{Na}$ doped $\mathrm{Ta}_{3} \mathrm{~N}_{5^{-}}$ nano porous structure. Electrochem. Commun. 17, 67-70 (2012).

31. Kado, Y. et al. Enhanced water splitting activity of $\mathrm{M}$-doped $\mathrm{Ta}_{3} \mathrm{~N}_{5}(\mathrm{M}=\mathrm{Na}, \mathrm{K}$, $\mathrm{Rb}, \mathrm{Cs})$. Chem. Commun. 48, 8685-8687 (2012).

32. Kanan, M. W. \& Nocera, D. G. In situ formation of an oxygen-evolving catalyst in neutral water containing phosphate and $\mathrm{Co}^{2+}$. Science 321, 1072-1075 (2008).

33. Steinmiller, E. M. \& Choi, K. S. Photochemical deposition of cobalt-based oxygen evolving catalyst on a semiconductor photoanode for solar oxygen production. Proc. Natl Acad. Sci. USA 106, $20633-20636$ (2009).

34. Reece, S. Y. et al. Wireless solar water splitting using silicon-based semiconductors and earth-abundant catalysts. Science 334, 645-648 (2011).

35. Zhong, D. K. et al. Photo-assisted electrodeposition of cobalt-phosphate (Co-Pi) catalyst on hematite photoanodes for solar water oxidation. Energ. Environ. Sci. 4, 1759-1764 (2011).

36. Klahr, B. et al. Photoelectrochemical and impedance spectroscopic investigation of water oxidation with 'Co-Pi'-coated hematite electrodes. J. Am. Chem. Soc 134, 16693-16700 (2012). 
37. Barroso, M. et al. Dynamics of photogenerated holes in surface modified $\alpha$ $\mathrm{Fe}_{2} \mathrm{O}_{3}$ photoanodes for solar water splitting. Proc. Natl Acad. Sci. USA 109, 15640-15645 (2012).

38. Gamelin, D. R. Water splitting: catalyst or spectator? Nat. Chem. 4, 965-967 (2012).

39. Kim, J. et al. Highly efficient overall water splitting through optimization of preparation and operation conditions of layered perovskite photocatalysts. Top. Catal. 35, 295-303 (2005).

\section{Acknowledgements}

This work was supported in part by a Grant-in-Aid for Specially Promoted Research (23000009) from Japan Society for the Promotion of Science (JSPS) and the Advanced Low Carbon Technology Research and Development Program (ALCA) of the Japan Science and Technology Agency (JST). Y.L. acknowledges support from JSPS as a postdoctoral fellow. P.O. and O.T. acknowledge VR, EXSELENT and 3DEM-NATUR, Sweden and WCU(R-31-2008-000-10055-0, Korea) for support. J.M.G.-C. and A.T.-P. acknowledge financial support by the Spanish Ministerio de Ciencia e Innovación (MAT201123068 and CSD2009-00013) and facilities provided by the National Centre for Electron Microscopy (UCM, Spain). Research by A.T.-P. has been also supported by a PICATA postdoctoral fellowship of the Moncloa Campus of International Excellence (UCM).

\section{Author contributions}

Y.L. fabricated the electrodes, conducted SEM, XRD and analysed the data, and carried out PEC experiments. Y.L. and L.Z. carried out the gas chromatography mesurements. A.T.-P., J.M.G.-C., Y.M., P.O., O.T., S.A., M.S., D.C., L.Z. and K.T. performed TEM, Cs-STEM, EDS, XPS and analysed the data. J.K. and K.D. conceived the project, supervised the research work and discussed the results. Y.L., O.T. and K.D. wrote the paper.

\section{Additional information}

Supplementary Information accompanies this paper at http://www.nature.com/ naturecommunications

Competing financial interests: The authors declare no competing financial interests

Reprints and permission information is available online at http://npg.nature.com/ reprintsandpermissions/

How to cite this article: Li, Y. et al. Cobalt phosphate-modified barium-doped tantalum nitride nanorod photoanode with $1.5 \%$ solar energy conversion efficiency. Nat. Commun. 4:2566 doi: $10.1038 /$ ncomms3566 (2013). 